\title{
Covid-19 Disease, Self-Isolation and Physical Inactivity
}

\author{
Mehmet UNAL ${ }^{1}$ and Tulay IREZ ${ }^{*}$ \\ ${ }^{1}$ Faculty of Health Science, Istanbul Yeni Yuzyil University, Turkey \\ ${ }^{2}$ Medical Faculty, Istanbul Yeni Yuzyil University, Turkey
}

*Corresponding author: Tulay IREZ, Medical Faculty, Istanbul Yeni Yuzyil University, Turkey

\begin{abstract}
The COVID-19 disease caused by the SARS-CoV-2 virus, which started in Wuhan, the capital of China's Hubei province, was declared a global epidemic by the World Health Organization. Restrictive measures based on physical (social) distance are taken to prevent the spread of the disease, which manifests itself with symptoms such as high fever, dry cough, shortness of breath, weakness, and diarrhea. According to the settlement rules, nationwide quarantines covering mass quarantine have proven effective in preventing the COVID-19 outbreak in most countries. The COVID-19 pandemic also causes mental health problems in many of the environments most affected by the pandemic due to the experience of illness, physical distances, stigma and discrimination, and job losses. Healthcare workers, COVID-19 patients and patients with other illnesses, children, women, youth, and the elderly experience post-traumatic stress disorders, anxiety, depression, and insomnia. Also, prolonged homestay and physical inactivation come with risks that can endanger people's health. As a result of physical inactivity. There are potentially undesirable risks of staying home for a long time, such as muscle atrophy, adipose tissue increase, and weight gain, exposure to insufficient sunlight, the emergence of cardiovascular diseases, suppression of the immune system, loneliness and behavioral disorders. The purpose of this article is to evaluate and discuss possible risks from physical inactivity.
\end{abstract}

\section{Keywords}

Coronavirus, SARS-CoV-2, COVID-19, Self-isolation, Physical inactivity, Sedentary behavior, Exercise, Epidemics

\section{Introduction}

Unfortunately, 2020 started with an epidemic that affected the world and killed many people. As a result of the increase in the number of patients admitted to clinics in Wuhan, China, research turned out to be a new Coronovirus epidemic. These viruses, called
SARS-CoV-2, can be transmitted from animal to animal and from animal to human [1,2]. As a result of genome analysis studies, it has been reported that SARS-CoV-2 is transmitted from bats to humans $[3,4]$. The infection of the microorganism in humans is mostly due to the respiratory droplets produced by infected individuals while talking, exhaling, coughing, or sneezing or the interaction of these droplets with the surfaces they touch [5]. The disease has been reported to cause fever, dry cough, shortness of breath and malaise, bilateral pneumonia [6] and intestinal infections [7], and dermatological rashes [8]. (WHO) confirms that SARS-CoV-2 is transmitted to approximately 107.686 .655 people worldwide, resulting in the deaths of 2.368 .571 people [9]. An effective treatment protocol established and the effectiveness of the vaccines developed are in dispute [10], with limiting physical contact and social isolation seems to be the most effective strategy to control the COVID-19 [11] outbreak for now. This strategy will limit the increase in morbidity, mortality, and demand in the health system, prevent the increase of new infections caused by person-to-person transmission and prevent accumulation in hospitals. However, home quarantine, introduced to limit physical contact and social isolation, is a serious problem such as Physical Inactivity (PI) [12]. Especially in old age, PI will make many activities that people can do in their daily life activities impossible and even if the quarantine period is extended at home, the losses will not come back. At the end of the home isolation period, PI (muscle atrophy, loss of flexibility, range of motion) or weight gain cause obesity, atherosclerosis, hypertension, type 2 diabetes, vitamin $D$ deficiency, osteoporosis, and arthrosis, etc. The COVID-19 outbreak has affected the lives of millions of people around

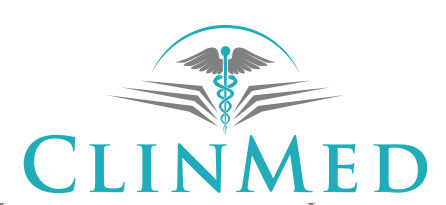

INTERNATIONAL LIBRARY 
the world and is likely to cause mental health problems among those without mental illness before and worsen the plight of pre-existing ones. Mental health problems will likely start early and continue after the epidemic is over [13]. While the experience of illness, disruption of social support, and stigma are possible causes of shortterm mental health problems, factors such as economic losses are thought to potentially cause long-term mental health problems [14-16]. Covid 19 has also created chaos in countries [17-19]. In Turkey, individuals over 65 years and young people under 20 years of age for 9 months and are given permission to go out only 3 hours daily. In this regard, states need to develop an urgent strategy to prevent mental problems and the negativity of inactive life. The purpose of this article is to discuss potential risks from physical inactivity due to global quarantine. This review aims to summarize the latest research findings and to provide expert consensus.

\section{SARS-CoV-2 and COVID-19 Disease}

Coronaviruses (CoV) are a large group of Coronaviridae families that cause a variety of diseases, from the common cold to more serious clinical manifestations such as Severe Acute Respiratory Syndrome (SARS-CoV) and the Middle East Respiratory Syndrome (MERS-CoV). These viruses act on the respiratory, gastrointestinal tract and central nervous systems of humans and animals [1,2]. They can infect humans and cause disease in humans. It has been reported that SARS-CoV-2 is transmitted from bats as a results of Genome analysis $[3,4]$. The SARS-CoV-2 infection, which started in Wuhan, the capital of China's Hubei province, was described by WHO as a pandemic on March 11, $2020[3,20]$. Although COVID-19 disease, which is associated with SARS-CoV-2, is initially thought to be a disease that causes fever, dry cough and dyspnea and subsequently pneumonia, it also causes gastrointestinal symptoms such as diarrhea, nausea, vomiting and dermatological rashes has been reported [6]. The incubation period of the disease has been reported as an average of 5.2 days (3-14 days) [9]. The disease is transmitted from person to person by direct inhalation of the droplets formed by coughing, sneezing or speech of sick people, or by direct or indirect contact of the sick person's respiratory secretion materials into the mouth, nose and eye mucous membranes of healthy people. It has been reported in recent publications that there may also be oral-faecal transmission [6]. SARS-CoV-2 uses Angiotensin Converting Enzyme 2 (ACE2) as a receptor for entry into ciliary bronchial epithelial cells and type-II pneumocytes [21].

Coronaviruses recognize the receptor in the target cell with $S$ protein and enter the cell and cause infection $[22,23]$. It is thought that SARS-CoV-2 also infects people by binding the S-protein to ACE2 [24].

Although the outbreak started in China, it is also quite common in Europe, America and other Asian countries [3]. Initially, after China, in most European countries, es- pecially Italy, Spain and France after the disease is common, while Russia, Turkey and began to be widely seen in Iran. The prevalent regions of the disease are seen in the USA, Brazil, Mexico and Peru.

Data from the European Center for Disease Prevention and Control (ECdC) [21] indicate that approximately $80 \%$ of cases with Covid-19 infection heal spontaneously $[25,26]$. It has been reported that $14 \%$ of infected cases have a more severe form of the disease, and $6 \%$ of them are critically ill. It has been determined that the majority of severe cases and deaths occur in the elderly and those with chronic conditions [27]. In the case of Italy, $50 \%$ of those who died as a result of Covid-19 are 70 -years-old or older. It has been observed that $25 \%$ of cases have two or $50 \%$ have 3 or more chronic diseases [28]. While $32 \%$ of Covid-19 patients have underlying diseases such as diabetes, hypertension and cardiovascular disease, the mortality rate in these cases has been reported to be $15 \%[29,30]$.

\section{Staying Home and Partial Quarantine Applica- tions}

Quarantine with dictionary meaning; it is a health measure applied to prevent entry and exit to control a specific area or place and prevent the spread of an infectious disease. Similarly, quarantine for an even period of infectious disease is carried out in measures taken by not contacting people and animals in a suspicious situation, the longest incubation period of the disease. The origin of the word is Italian [31].

There is no specific antiviral drug therapy or vaccine available for Covid-19 therapy [32]. Currently, Covid-19 therapy is limited to supportive and palliative therapy. It is necessary to prevent transmission of the virus from person to person, to pay attention to social distance (should be at least $1.5 \mathrm{~m}$ away if possible) and not to leave the house, to prevent disease contamination and spread [33]. When the cases that result in death are examined, the average age is high and they have more than one chronic disease, while in the absence of any chronic disease, young people rarely risk death. Given that all different age groups are at risk of SARS-CoV-2 infection, it is important that all young individuals with mild or asymptomatic disease also follow self-isolation procedures to prevent the spread of the virus [34]. National quarantine practice has proven effective in most countries to slow down the COVID-19 outbreak and reduce the number of cases, according to residence rules $[35,36]$.

These days China as well as Great Britain, Italy, Spain, France, Germany, South Africa, India, Colombia, New Zealand, by more than 50 countries in which the US and Turkey to to limit the spread of SARS-CoV-2 infection in the country restrictions are applied and people are encouraged to work from home. This strategy has been proved to be effective in curbing the COVID-19 
outbreak in China and also limits the export of infected cases abroad $[37,38]$. When looking at the populations of countries applying partial quarantine, it can be estimated that more than half of humanity has been subjected to some kind of restrictive measures [39]. However, when home-stay, partial quarantine continues for a long time, it can present many problems related to inactivation and social isolation, disrupt social habits and endanger personal health.

\section{Physical Activity}

Physical Activity (PA) are physical movements that require energy to be produced as a results of contraction of skeletal muscles and spend energy above basal level. Regular, planned structured form of FA is called exercise [38]. Studies have shown that PA prolongs life and reduces the risk of mortality [39]. Exercise has positive effects on all systems in our body, from the cardiovascular system to the respiratory system, from the endocrine system to the nervous system, from the immune system to the musculoskeletal system functions $[40,41]$. It has been shown that cardiovascular risk factors can be reduced with PA [42]. Similarly, FAs have been reported to improve blood lipid profile, lower blood pressure, increase insulin sensitivity, improve C-reactive protein and other chronic heart disease biomarkers and strengthen the immune system $[42,43]$. In addition, when PA is supplemented with diet, it is an important part of weight control [44]. There are publications showing that PA plays a protective role in some types of cancer [45].

It is known that FAs have positive effects on the immune system [46]. Regular aerobic exercises have been shown to increase NK cell numbers and functions, alter CD4 T cells/CD8 T cells ratios, increase the levels of immunoglobulin M (IgM) and IgG, thereby increasing a person's resistance to infections [47,48]. Physical activities of different intensity have different effects on the immune system $[49,50]$. Many studies have shown that inflammatory factors such as plasma interleukin-6 (IL-6), tumor necrosis factor-alpha (TNF- $\alpha$ ) and Aspartate Aminotransferase (AST) levels of medium-intensity aerobic exercises and high-intensity interval training (HIIT) has shown to have a positive effect [51,52] and improve immune function biomarkers [52].

Since FAs protect the person's mental health as well as their immune system $[53,54]$, they can help people cope with COVID-19-related stress and reduce their harmful effects on health $[55,56]$. In addition, it has been shown that sufficient FA decreases depression and fall rates, increases physical fitness of the circulatory, respiratory and musculoskeletal systems, improves well-being and cognitive functions [57]. These findings reveal the need to suggest moderate intensity exercise as a non-pharmacological, inexpensive and feasible way to deal with the SARS-CoV-2 virus. Measures in the isolation process, including the closure of gyms, the absence of going out with the fear of disease transmission, de- creasing the number of arrivals to work, people preferring private vehicles away from public transportation due to viruses and increasing the opportunity to work at home, significantly disrupted the daily routines, negatively affected. It appears that all studies on COVID-19 infection focus on the treatment of the disease and termination of the pandemic. But at least as much as the Covid-19 Pandemic, perhaps more than the health and economic destruction of the Covid-19 pandemic will come up with physical inactivation.

\section{Physical Inactivity}

Concepts such as Physical Inactivity (PI), social distance, self-isolation and isolation at home have now become part of our daily lives $[58,59]$. Unfortunately, self-isolation finds global support to prevent the spread of Covid-19 disease. Due to the fear of being infected, opportunities to stay physically active have been reduced. While PI is defined as a factor that negatively affects health, WHO is defined as a pandemic, Covid-19 increased the number of physically inactive individuals due to self-isolation, on-site accommodation and working at home [60]. Today, before Covid-19, 31\% of individuals over the age of 15 in the world are estimated to be physically inactive, and about 3.2 million people die annually due to PI [61]. $41 \%$ of these individuals spend time sitting more than 4 hours a day [61]. Ding, et al. in a study they did in 2013, they reported to the health care systems worldwide that the cost of PI was around $\$ 53.8$ billion. In addition, $\mathrm{PI}$-related deaths result in cost losses of $\$ 13.7$ billion due to loss of productivity [62]. Applying mass quarantine globally according to the rules of residence will lead to more physical inactivation problems.

Since $\mathrm{PI}$ is known to increase the risk of chronic diseases such as obesity, cardiovascular diseases (heart attack, stroke, etc.), Cancers, osteoporosis, COPD, asthma and diabetes, $\mathrm{PI}$ is considered a global pandemic [60]. Chronic diseases are long-term diseases that result from a combination of genetic, psychological, environmental and behavioral factors. According to the data published by WHO in 2018, it is seen that 41 million people die every year due to chronic diseases and this figure constitutes $71 \%$ of all deaths. Although chronic diseases are generally associated with the elderly population, 15 million of deaths from chronic diseases are reported to be between the ages of 30-69 and 85\% of these 'early' deaths occur in low- and middle-income countries [63]. Considering that $\mathrm{PI}$ increases the rates of contracting chronic diseases, it is clear that self-isolation application will prevent the spread of Covid-19 and worsen the situation in terms of chronic diseases.

Almost all of the risk factors originating from PI are exchangeable factors, and chronic diseases that may develop with appropriate behavioral changes can be prevented. In addition to behaviors such as smoking cessation, healthy eating and reducing alcohol consumption, regular PAs have been proven to be effective in prevent- 
ing and preventing diseases [64]. In a study conducted on 416,715 individuals in Taiwan, individuals who were physically active showed a $14 \%$ lower risk of mortality than individuals who were not. This figure was $35 \%$ lower in physically active individuals [65]. According to WHO's 2009 data, PI ranks $4^{\text {th }}$ among $6 \%$ of all deaths in the world. As a result of understanding the harmful effects of PI on health, countries have started to develop health policies to increase PA habit. Despite this, globally sufficient gains have not been achieved in terms of providing an active lifestyle to prevent diseases [66].

One of the most negative consequences of $\mathrm{PI}$ is the risk of developing obesity due to excess weight gain [24]. Overweight and obesity [67] increase the risk of many pathologies such as diabetes, cardiovascular diseases, pulmonary embolism, cancers and osteoarthritis [68]. COVID-19 is a disease with a higher risk for obese people [69]. The negative clinical effects of $\mathrm{PI}$ in obese include muscle atrophy, weakness, fatigue, insulin resistance, dyslipidemia, decreased physical capacity and low quality of life [70]. Being in a closed environment for long periods of time causes exposure to insufficient sunlight and then deficiency of vitamin D. Vitamin D is not only necessary for bone health [71]. It also has a wide range of effects, including reducing the risk of developing pathologies such as cardiovascular and autoimmune diseases, cancer, allergies and asthma, mental disorders, metabolic syndrome and diabetes [72]. Vitamin D also improves the immune system. People with vitamin $D$ deficiency have been shown to be at increased risk of developing respiratory infections [73]. SARS-CoV-2 is mainly a pathogen which causes respiratory infections [74], vitamin D deficiency can render severe course of the disease Covid-19 [75].

Another physical problem associated with Covid-19 disease is impaired motor function. Impaired motor function may be related to Covid-19 disease or may be associated with prolonged immobilization due to muscle atrophy. Common musculoskeletal pain, weakness, fatigue and fatigue seen in Covid-19 disease can also contribute to muscle atrophy. With decreased endurance due to muscle atrophy, cardiopulmonary exercise capacity decreases. Many patients also experience varying degrees of psychiatric disorders such as anxiety and depression both in the acute and recovery periods [76]. When the literature information is examined, it can be seen that anxiety and depression are factors that can worsen dyspnea and pulmonary functions. Pulmonary rehabilitation programs and exercises have been shown to have positive effects on dyspnea, respiratory functions, anxiety, depression, and quality of life [77].

In $11.8 \%$ of cases that died from COVID-19 reported by the Chinese National Health Commission, serious cardiac damage, high cardiac biomarkers, or cardiac arrest during hospitalization were shown, although no cardiovascular disease was previously found. There- fore, patients with COVID-19 have a high incidence of cardiovascular symptoms due to systemic inflammatory response and immune system disorders during disease progression. While COVID-19 disease causes pneumonia in the lungs, it causes acute myocardial injury or chronic damage in the future in the cardiovascular system [78]. Being physically active due to the protective gains of PA on the cardiovascular system and respiratory system and its ability to activate the immune system will contribute to the protection of our cardiovascular system before, during and after treatment of COVID-19 disease.

Spending longer time inevitably watching television, playing computer games, or surfing in social networks can remain potentially behavioral addiction disorders. The most common side effects of long-term home isolations are psychological disorders (eg sleep deprivation, self-harm), neurological complications (eg eye fatigue, headache), musculoskeletal system disorders (eg neck, back, low back pain, carpal tunnel syndrome) $[79,80]$ and venous thrombosis associated with immobility [81].

As the epidemic spreads, many countries increase their self-isolation measures, and the number of people isolated at home increases in parallel. Today, it has been found that social isolation should be seen as a basic public health problem in the elderly, as it increases the burden of neurocognitive, mental, cardiovascular and autoimmune problems as well as depression and anxiety [82]. Moreover, recent publications have shown that inactive behavior in young people can be an important cause of depression and anxiety [83]. Therefore, self-isolation should be seen as a global health and social problem.

\section{Applications that can be done to avoid the Damages of Physical Inactivity}

As of May 27, 2020, there are 107.686.655 Covid-19 cases and 2.368.571 deaths worldwide. Covid-19 cases that will be diagnosed in the future, considering the possible $2^{\text {nd }}$ and $3^{\text {rd }}$ waves, may increase the number of cases [9]. And if this is not a specific treatment protocol or vaccine, it may increase the partial quarantine time to stay at home as well as the PI time. For this reason, the individuals should be told about the harms of the PI and how they can urgently start and exercise their personally prepared exercise programs. Here, media and social media should be widely used and home exercise programs should be implemented in the form of tele-exercise videos.

Social isolation applied due to Covid-19 has prevented us from doing many physical activities that are in our daily routine, to a lesser extent. Sleeping longer hours, spending more time in front of television, computer games, social media, you-tube activities have restricted our physical activities, but also changed our eating habits. A few weeks of immobilization has been shown to cause atrophy and function in the heart muscle [84], 
narrowing and stiffening of the peripheral vessels [85], and disruption in macro and microcirculation $[86,87]$. Before the COVID-19 outbreak, the rate of PI among patients with Coronary Heart Disease (CHD) is $22.3-40.5 \%$ worldwide [12]. Social isolation due to Covid-19 and the accompanying PI will increase these rates by multiplying.

For global health promotion, WHO recommends that adults do 150 minutes of moderate-intensity aerobic physical activity per week or 75 minutes or more of intensive intensity aerobic physical activity per week [11]. In addition, WHO recommends performing muscle strengthening activities involving large muscle groups 2 or more days a week. These suggestions are to do physical activities such as walking, cycling, swimming, gardening, walking, dancing and housework for $30 \mathrm{~min}$ utes a day. It has been shown that moderate intensity exercises cause a $24 \%$ reduction in cardiovascular mortality rates [88] and decrease the risk of obesity, insulin resistance, type 2 diabetes and stroke [89]. Social isolation measures implemented to prevent the spread of Covid-19 are naturally difficult for individuals living in quarantine areas to implement, since the movement of individuals outside the home is almost completely prohibited. People who are forced to stay in their homes for weeks (or even months) may only occasionally move for compulsory needs or nutritional purposes. In order to minimize the harmful effects of PI that may arise in this situation, it should be suggested to encourage participation in some indoor physical activities. Although it is not possible for the majority of people with fast walking, running and cycling, indoor exercise equipment (such as treadmills, stationary bikes, etc.), movements with body weight, staircase up and down, walking, exercise bands with exercise ball or simple weights, strength and aerobic exercises can be done without the need for very special and expensive equipment [90]. Exercise training without equipment can be done through television, video or you-tube channels [91]. Here it is appropriate for everyone to make a PA, which is modified according to their age group, physical characteristics, condition and existing chronic diseases. Going up and down stairs, doing step exercises, jumping, doing sit-ups, or even doing strength training with simple tools that can be found at home can help individuals and protect against harmful effects from prolonged physical inactivity. The importance of avoiding all kinds of sports injuries while exercising should be emphasized here [92]. It is very important not only to increase the burden of hospitals unnecessarily but also to reduce the number of hospital admissions in terms of preventing the spread of SARS-CoV-2, which is widely used in hospitals, especially emergency services [93].

\section{Conclusion}

As a result, Covid-19 is an important and serious picture of viral infection caused by SARS-CoV-2. It has high transmission speed. In some patients, life threatens global health and safety in the community. Therefore, it is the most important goal to prevent the spread of the disease and reduce mortality until a specific treatment or vaccine is obtained. Social isolation is important because asymptomatic individuals have a high potential to spread the disease. Staying at home, partial quarantine practices and Covid-19 pandemics implemented to prevent the spread of the disease trigger another outbreak and ignite the wick of many diseases that may arise due to PI. We need to organize these two outbreaks very well. When trying to eliminate one, one should not trigger the other, which will lead to much more dangerous consequences. Strategies such as "move more and sit less" to patients at risk should be recommended, at least to reduce the harmful effects of the inactivity they are exposed to during self-isolation and to prevent longterm immobility [94].

The PI pandemic will continue for a long time, even after getting rid of the COVID-19 pandemic. The negative effects of the endless Covid-19 pandemic on health and the economy will continue with intensification. In fact, the recommendations made to minimize the harmful effects of the Covid 19 pandemic are quite innocent. A medium intensity PA [95] of 150 minutes or more per week is sufficient to eliminate problems caused by PI. As few as 4000 steps a day at any speed has been shown to improve long-term health $[96,97]$. Each additional hour of sitting is estimated to result in an increase of $\$ 126$ in annual health costs for older adults [98]. In fact, the 2018 US Physical Activity Guidelines have confirmed the harmful effect of long-term sitting time, and any decrease in PI and increase in FA, even if this increase is below the recommended target, has been reported to have a significant benefit to health [94]. The COVID-19 pandemic will accelerate the PI pandemic, which we have been facing for a long time, and which we have not bent on very much. Due to the COVID-19 pandemic, many opportunities to be physically active, including fitness centers, public parks and hiking trails, have been suspended. As a result, during the Covid-19 pandemic, people who already tend to be inactive have become more inactive than before. Home isolation applied to prevent the spread of SARS-CoV-2 can lead patients to adopt a sedentary lifestyle and also lead to obesity, joint disorders, vitamin D deficiency, osteopenia, osteoporosis, muscle atrophy, decreased functional capacity, behavioral changes and depression. Having to adopt the lifestyle of the community at home will speed up the PI pandemic and increase its harmful effects. The lesson from the Covid-19 pandemic seems to require a global organization similar to the COVID-19 pandemic in order to eliminate the economic burden of Covid-19 disease and PI pandemics that are at least as harmful as Covid-19 disease. 


\section{References}

1. Unal M, Irez T (2020) COVID 19 Disease Caused by Coronavirus 2 (SARSCoV-2) (Severe Acute Respiratory Syndrome) 18: 1-11, Article no. AJMAH.56613 ISSN: 24568414.

2. Xu J, Zhao S, Teng T, Abdalla AE, Zhu W, et al. (2020) Systematic comparison of two animalto-human transmitted human coronaviruses:SARS-CoV-2 and SARS-CoV. Viruses 12: 244 .

3. World Health Organization (2020) Coronavirus disease 2019 (COVID-19) Situation Report-40.

4. https://covid19bilgi.saglik.gov.tr/tr/

5. Lippi G, Henry BH, Bovo C, Sanchis-Gomar F (2020) Health risks and potential remedies during prolonged lockdowns for coronavirus disease 2019 (COVID-19). Diagnosis 7: 8590 .

6. Khan S, Siddique R, Shereen MA, Ali A, Liu J, et al. (2020) The emergence of a novel coronavirus (SARS-CoV-2), their biology and therapeutic options. JCM J Clin Microbiol.

7. To KK, Tsang OT, Chik-Yan Yip C, Chan KH, Wu TC, et al. (2020) Consistent detection of 2019 novel coronavirus in saliva. Clin Infect Dis 71: 841-843.

8. Van Doremalen N, Bushmaker T, Morris DH, Holbrook MG, Gamble A, et al. (2020) Aerosol and surface stability of SARS-CoV-2 as compared with SARS-CoV-1. N Engl J Med.

9. World Health Organization (2021) Coronavirus disease (COVID-19) Pandemic.

10. Vardavas Cl, Nikitara K (2020) COVID-19 and smoking: A systematic review of the evidence. Tob Induc Dis 18: 20.

11. World Health Organization (2020) Physical activity and adults.

12. Peçanha T, Goessler KF, Roschel H, Gualano B (2020) Social Isolation During The Covid-19 Pandemic Can Increase Physical Inactivity And The Global Burden Of Cardiovascular Disease. Am J Physiol Heart Circ Physiol 318: 14411446.

13. Gautam R, Manik S (2020) 2019-nCoV pandemic: A disruptive and stressful atmosphere for Indian academic fraternity. Brain Behav Immun 88: 948-949.

14. Sharma, S, Manik S, Gurvinder S (2020) A chaotic and stressed environment for 2019-nCoV suspected, infected and other people in India: Fear of mass destruction and causality. Asian J Psychiatr 51: 102049.

15. Monga P, Manik S, Sanjeev KS (2020) Need of surveillance system to support digital psychological intervention to COVID19 afflicted people in India. Int J Soc Psychiatry.

16. Sharma M (2020) Design of brain-computer interface-based classification model for mining mental state of COVID-19 afflicted mariner's. Int Marit Health 71: 298-300.

17. Tirachini A, Oded C (2020) COVID-19 and public transportation: Current assessment, prospects, and research needs. Journal of Public Transportation 22: 1.

18. Chris H, Rilett LR (2020) The COVID-19 pandemic and transportation engineering. 01820001.

19. Ben W, Eynon R, Potter J (2020) Pandemic politics, pedagogies and practices: digital technologies and distance education during the coronavirus emergency. Learning, Media and Technology 45: 107-114.
20. Dong E, Du H, Gardner L (2020) An interactive web-based dashboard to track COVID-19 in real time. Lancet Infect Dis 20: 533-534.

21. Qian Z, Travanty EA, Oko L, Edeen K, Berglund A, et al. (2013) Innate immune response of human alveolar type II cells infected with severe acute respiratory syndrome-coronavirus. Am J Respir Cell Mol Biol 48: 742-748.

22. Liu Z, Xiao X, Wei X, Li J, Yang J, et al. (2020) Composition and divergence of coronavirus spike proteins and host ACE2 receptors predict potential intermediate hosts of SARSCoV-2. J Med Virol.

23. Wrapp D, Wang N, Corbett KS, Goldsmith JA, Hsieh CL, et al. (2020) Cryo-EM structure of the 2019-nCoV spike in the prefusion conformation. Science 367: 1260-1263.

24. Palacios Cruz M, Santos E, Velázquez Cervantes MA, León Juárez M (2020) COVID-19, a worldwide public health emergency. Rev Clin Esp 221: 55-61.

25. Wang W, Tang J, Wei F (2020) Updated understanding of the outbreak of 2019 novel coronavirus (2019-nCoV) in Wuhan, China. J Med Virol 92: 441-447.

26. Guan WJ, Ni ZY, Hu Y, Liang WH, Ou CQ, et al. (2020) Clinical characteristics of coronavirus disease 2019 in China. N Engl J Med.

27. Ding D, Zhu C, Yao W (2020) A cured patient with 2019nCoV pneumonia. Am J Med 133: 1291-1292.

28. Roser M, Ritchie H (2020) Coronavirus Disease (COVID-19). Our World in Data.[cited 2020 Mar 10].

29. Prajapat M, Sarma $P$, Shekhar N, Avti P, Sinha S, et al. (2020) Drug targets for corona virus: A systematic review. Indian J Pharmacol 52: 56-65.

30. WHO (2020) Report of the WHO-China Joint Mission on Coronavirus Disease 2019 (COVID-19).

31. https://www.dictionary.com/e/quarantine-vs-isolation/

32. Lim CC, Tan CS, Kaushik M, Tan HK (2015) Initiating acute dialysis at earlier Acute Kidney Injury Network stage in critically ill patients without traditional indications does not improve outcome: a prospective cohort study. Nephrology (Carlton) 20: 148-154.

33. Yuen KS, Ye ZW, Fung SY, Chan CP, Jin DY (2020) SARSCoV-2 and COVID-19: The most important research questions. Cell Biosci 10: 40.

34. Li R, Pei S, Chen B, Song Y, Zhang T, et al. (2020) Substantial undocumented infection facilitates the rapid dissemination of novel coronavirus (SARS-CoV2). Science 368: 489-493.

35. Lau H, Khosrawipour V, Kocbach P, Mikolajczyk A, Schubert J, et al. (2020) The positive impact of lockdown in Wuhan on containing the COVID-19 outbreak in China. J Travel Med 27: 037.

36. Wells CR, Sah P, Moghadas SM, Pandey A, Shoukat A, et al. (2020) Impact of international travel and border control measures on the global spread of the novel 2019 coronavirus outbreak. Proc Natl Acad Sci USA.

37. Cui J, Li F, Shi ZL (2019) Origin and evolution of pathogenic coronaviruses. Nat Rev Microbiol 17: 181-192.

38. https://www.who.int/topics/physical_activity/en/

39. Morris JN, Heady JA, Raffle PA, Roberts CG, Parks JW (1953) Coronary heart-disease and physical activity of work. Lancet 265: 1053-1057. 
40. Ünal M, Erdem S, Deniz G (2005) The Effects Of Chronic Aerobic And Anaerobic Exercises On Lymphocyte Subgroups. Acta Physiol Hung 92: 163-171.

41. Klenk J, Denkinger M, Nikolaus T, Peter R, Rothenbacher D, et al. (2013) Association of Objectively Measured Physical Activity With Established and Novel Cardiovascular Biomarkers in Elderly Subjects: Every Step Counts. J Epidemiol Community Health 67: 194-197.

42. Vanhees L, Sutter J De, Geladas N, Doyle F, Prescott E, et al. (2012) Importance of Characteristics and Modalities of Physical Activity and Exercise in Defining the Benefits to Cardiovascular Health Within the General Population: Recommendations From the EACPR (Part I). Eur J Prev Cardiol 19: $670-686$.

43. de Torres JP, Cordoba-Lanus E, López-Aguilar C, Muros de Fuentes M, Montejo de Garcini A, et al. (2006) C-reactive Protein Levels and Clinically Important Predictive Outcomes in Stable COPD Patients. Eur Respir J 27: 902-907.

44. Goldberg JH, King AC (2007) Physical Activity and Weight Management Across the Lifespan. Annual Review of Public Health 28: 145-170.

45. Anzuini F, Battistella A, Izzotti A (2011) Physical Activity and Cancer Prevention: A Review of Current Evidence and Biological Mechanisms. J Prev Med Hyg 52: 174-180.

46. Salman F, Erten G, Ünal M, Kiran B, Salman S, et al. (2008) Effect of Acute Maximal Exercise on Lymphocyte Subgroups in Type I Diabetes. Acta Physiol Hung 95: 77-86.

47. Thevarajan I, Nguyen THO, Koutsakos M, Druce J, Caly L, et al. (2020) Breadth of concomitant immune responses prior to patient recovery: a case report of non-severe COVID-19. Nat Med 26: 453-455.

48. Nieman DC, Wentz LM (2019) The compelling link between physical activity and the body's defense system. J Sport Health Sci 8: 201-217.

49. Romeo J, Warnberg J, Pozo T, Marcos A (2010) Physical activity, immunity and infection. Proc Nutr Soc 69: 390-399.

50. Khaleghzadeh H, Afzalpour ME, Ahmadi MM, et al. (2020) Effect of high intensity interval training along with Oligopin supplementation on some inflammatory indices and liver enzymes in obese male Wistar rats with non-alcoholic fatty liver disease. Obesity Medicine.

51. Taheri Chadorneshin H, Cheragh-Birjandi S, Goodarzy S, et al. (2019) The impact of high intensity interval training on serum chemerin, tumor necrosis factor-alpha and insulin resistance in overweight women. Obesity Medicine 14100101.

52. Khammassi M, Ouerghi N, Said M, Feki M, Khammassi $Y$, et al. (2020) Continuous Moderate-Intensity but Not HighIntensity Interval Training Improves Immune Function Biomarkers in Healthy Young Men. J Strength Cond Res 34: 249-256.

53. Rebar AL, Stanton R, Geard D, Short C, Duncan MJ, et al. (2015) A meta-meta-analysis of the effect of physical activity on depression and anxiety in non295 clinical adult populations. Health Psychology Review 9: 366-378.

54. Warburton DE, Nicol CW, Bredin SS (2006) Health benefits of physical activity: theevidence. CMAJ 174: 801-809.

55. Boberska M, Szczuka Z, Kruk M, Knoll N, Keller J, et al. (2018) Sedentary behaviours and health-related quality of life. A systematic review and meta-analysis. Health Psychol Rev 12: 195-210.

56. Ekelund U, Steene-Johannessen J, Brown WJ, Fagerland
MW, Owen N, et al. (2016) Does physical activity attenuate, or even eliminate, the detrimental association of sitting time with mortality? A harmonised meta-analysis of data from more than 1 million men and women. Lancet 388: 13021310.

57. Kohl HW (2012) The pandemic of physical inactivity: global action for public health. Lancet 380: 294-305.

58. Merriam-Webster. Social Distancing.

59. Miller K (2020) Here's what a shelter in place order means during the Coronavirus Pandemic.

60. Kohl 3rd HW, Craig CL, Lambert EV, Inoue S, Alkandari JR, et al. (2012) The pandemic of physical inactivity: global action for public health. Lancet 380: 294-305.

61. Hallal PC (2012) Global Physical Activity Levels: Surveillance Progress, Pitfalls, and Prospects. Lancet 380: 247257.

62. Ding D, Lawson KD, Kolbe Alexander TL, Finkelstein EA, Katzmarzyk PT, et al. (2016) The economic burden of physical inactivity: a global analysis of major non-communicable diseases. Lancet 388: 1311-1324.

63. WHO, Cenevre (2020) Global physical activity questionnaire (GPAQ) analysis guide.

64. https://www.who.int/news-room/fact-sheets/detail/noncommunicable-diseases

65. Wen CP, Wai JPM, Tsai MK, Yang CY, Cheng TYD, et al. (2011) Minimum Amount of Physical Activity for Reduced Mortality and Extended Life Expectancy: A Prospective Cohort Study. Lancet 378: 1244-1253.

66. Andersen LB, Mota J, Pietro LD (2016) Update on the global pandemic of physical inactivity. Lancet 388: 1255-1256.

67. World Health Organization (2020) Obesity and overweight.

68. Djalalinia S, Qorbani M, Peykari N, Kelishadi R (2015) Health impacts of obesity. Pak J Med Sci 31: 239-242.

69. Rahmati-Ahmadabad S, Hosseini F (2020) Exercise against SARS-CoV-2 (COVID-19): Does workout intensity matter? (A mini review of some indirect evidence related to obesity). Obes Med 19: 100245.

70. Gualano B, Bonfa E, Pereira RMR, Silva CA (2017) Physical activity for paediatric rheumatic diseases: standing up against old paradigms. Nat Rev Rheumatol 13: 368-379.

71. Lippi G, Targher G (2019) Are we overrating the extra-skeletal benefits of oral vitamin D supplementation? Ann Transl Med 7: 499.

72. Targher G, Pichiri I, Lippi G (2012) Vitamin D, thrombosis, and hemostasis: more than skin deep. Semin Thromb Hemost 38: 114-124.

73. Beard JA, Bearden A, Striker R (2011) Vitamin D and the anti-viral state. J Clin Virol 50: 194-200.

74. Moriyama M, Hugentobler WJ, Iwasaki A (2020) Seasonality of respiratory viral infections. Annu Rev Virol 7: 83-101.

75. Kennel KA, Drake MT, Hurley DL (2010) Vitamin D deficiency in adults: when to test and how to treat. Mayo Clin Proc 85: $752-757$.

76. Lei L, Huang X, Zhang S, Yang J, Yang L, et al. (2020) Comparison of Prevalence and Associated Factors of Anxiety and Depression Among People Affected by versus People Unaffected by Quarantine During the COVID-19 Epidemic in Southwestern China. Med Sci Monit 26: e9246091- e924609-12. 
77. Li J (2020) Effect and enlightenment of rehabilitation medicine in COVID-19 management. European Journal of Physical and Rehabilitation Medicine.

78. Zhang JJ (2020) Clinical characteristics of 140 patients infected with SARS-CoV-2 in Wuhan, China. Allergy 75: 1730-1741.

79. Cash H, Rae CD, Steel AH, Winkler A (2012) Internet addiction: a brief summary of research and practice. Curr Psychiatry Rev 8: 292-298.

80. World Health Organization (2014) Public health implications of excessive use of the internet, computers, smartphones and similar electronic devices. Geneva, Switzerland: WHO Press, World Health Organization.

81. Lippi G, Mattiuzzi C, Favaloro EJ (2018) e-thrombosis: epidemiology, physiopathology and rationale for preventing computer-related thrombosis. Ann Transl Med 6: 344.

82. Armitage R, Nellums LB (2020) COVID-19 and the consequences of isolating the elderly. Lancet Public Health.

83. Belair MA, Kohen DE, Kingsbury M, Colman I (2018) Relationship between leisure time physical activity, sedentary behaviour and symptoms of depression and anxiety: evidence from a population-based sample of Canadian adolescents. BMJ Open 8: e021119.

84. Platts SH, Martin DS, Stenger MB, Perez SA, Ribeiro LC, et al. (2009) Cardiovascular Adaptations to Long-Duration Head-Down Bed Rest. Aviat Space Envir Md 80: A29-A36.

85. Palombo C, Morizzo C, Baluci M, Lucini D, Ricci S, et al. (2015) Large Artery Remodeling and Dynamics following Simulated Microgravity by Prolonged Head-Down Tilt Bed Rest in Humans. Biomed Res Int 2015: 342565.

86. Demiot C, Dignat-George F, Fortrat JO, Sabatier F, Gharib C, et al. (2007) WISE 2005: chronic bed rest impairs microcirculatory endothelium in women. Am J Physiol Heart Circ Physiol 293: 3159-3164.

87. Sonne MP, Hojbjerre L, Alibegovic AC, Nielsen LB, Stallknecht B, et al. (2011) Endothelial function after 10 days of bed rest in individuals at risk for type 2 diabetes and cardiovascular disease. Exp Physiol 96: 1000-1009.
88. Dohrn IM, Kwak L, Oja P, Sjostrom M, Hagstromer M (2018) Replacing sedentary time with physical activity: a 15-year follow-up of mortality in a national cohort. Clin Epidemiol 10: $179-186$.

89. Koster A, Savelberg HH (2017) Breaking sitting with light activities vs structured exercise: a randomised crossover study demonstrating benefits for glycaemic control and insulin sensitivity in type 2 diabetes. Diabetologia 60: 490498.

90. Caner ZG, Ünal M, Apaydın Z, Dağ A, Okur Ş, et al. (2020) COVID-19 Disease and the Importance of Home Exercises. Journal of Medical Sciences 3: 30-37.

91. Sullivan AN, Lachman ME (2016) Behavior change with fitness techno- logy in sedentary adults: a review of the evidence for increasing physical activity. Front Public Health 4: 289.

92. Maffulli N, Del Buono A, Oliva F, Giai Via A, Frizziero A, et al. (2015) Muscle injuries: a brief guide to classification and management. Transl Med UniSa 12: 14-18.

93. Fisher D, Heymann D (2020) Q\&A: the novel coronavirus outbreak caus-ing COVID-19. BMC Med 18: 57.

94. Pinto AJ, Roschel $H$, de Sá Pinto AL, Lima FR, Pereira RMR, et al. (2017) Physical inactivity and sedentary behavior: overlooked risk factors in autoimmune rheumatic diseases? Autoimmun Rev 16: 667-674.

95. Piercy KL, Troiano RP, Ballard RM, Carlson SA, Fulton JE, et al. (2018) The physical activity guidelines for Americans. JAMA 320: 2020-2028.

96. Saint-Maurice PF, Troiano RP, Bassett Jr DR, Graubard BI, Carlson SA, et al. (2020) Association of daily step count and step intensity with mortality among US adults. JAMA 323: $1151-1160$.

97. Hall G, Laddu DR, Phillips SA, Lavie CJ, Arena R (2020) A tale of two pandemics: How will COVID-19 and global trends in physical inactivity and sedentary behavior affect one another? Prog Cardiovasc Dis.

98. Rosenberg D, Cook A, Gell N, Lozano P, Grothaus L, et al. (2015) Relationships be- tween sitting time and health indicators, costs, and utilization in older adults. Prev Med Rep 2: 247-249. 